\title{
Marco A. Calderón Mólgora y Elizabeth M. Buenabad (eds.) (2012), Educación indigena, ciudadanía y Estado en México: siglo xx, El Colegio de Michoacán-Instituto de Ciencias Sociales y Humanidades "Alfonso Vélez Pliego", Benemérita Universidad Autónoma de Puebla, México
}

\author{
Ulrike Keyser Ohrt \\ Profesora-investigadora \\ Universidad Pedagógica Nacional, \\ Unidad 162, Zamora, Mich \\ ulikeyser@hotmail.com
}

Antes de referirme al contenido de esta obra, quiero comentar sobre dicho libro como objeto material y atracción para el sentido visual. La portada, diseñada en gris, negro y rojo, integra una foto de dos niños, hermanos y posiblemente receptores de la educación que en su tiempo dirigía el Estado a indígenas para formarlos como ciudadanos. El título de la foto es "Celestino y su hermano bebé". Entre ambos se nota mucha cercanía y seguridad, muestra de que el niño mayor ya aprendió a cuidar a su pequeño hermano. En la mirada sonriente de Celestino, hay apertura, mientras que la del "bebé" es reservada, sin mucha confianza hacia el extranjero que los está retratando: Ricardo Barthelemy. Desde esta primera mirada al libro, surge la curiosidad de saber cómo presentará lo que promete el título.

El índice consigna una división en dos secciones: la primera está dedicada a "Educación rural y ciudadanía”; comprende cinco colaboraciones: cuatro mujeres y un hombre, quienes abordan distintas épocas entre finales de los siglos XIX y principios del XX, si bien casi todos centran sus investigaciones en la primera mitad del siglo pasado. La segunda sección del libro se denomina "Influencias teóricas e ideológicas sobre políticas de cambio cultural dirigido"; la conforman tres textos (de dos autores y una autora, respectivamente), que ubican sus estudios durante las décadas de los años veinte y treinta del siglo Xx. Los colaboradores son especialistas de distintas disciplinas.

El libro reúne diferentes miradas y fuentes para hablar de los tiempos posrevolucionarios, cuando se generan las bases de un Estado y se establecen las primeras relaciones con los ciudadanos que marcarán las políticas públicas hasta la actualidad. Educación indígena, ciudadanía y Estado en México: siglo xx es un libro cuidadosamente editado que ofrece lecturas 
bien presentadas y fundamentadas, atractivo para estudiosos e interesados en la historia de la educación para indígenas, así como en su formación como ciudadanos mexicanos.

A partir de mi interés por la educación de indígenas, es decir, lo que los indígenas han desarrollado para educarse a sí mismos en escuelas y fuera de éstas, así como la educación para indígenas, lo que el Estado ha diseñado para educarlos, formulé tres primeras preguntas a estos trabajos: ¿qué buscaron o encontraron los participantes en este volumen en relación con la educación de y para indígenas? En cuanto al tema de la ciudadanía, me pregunté: ¿cuáles conceptos de ciudadanía presentan? Finalmente, me interesé en detectar ¿desde cuál perspectiva - desde la de los ciudadanos o desde la del Estado- se presentan en los textos las relaciones de los ciudadanos con el Estado? A partir de estas preguntas comentaré los distintos textos que conforman este libro.

\section{Primera sección}

En "Ciudadanos indígenas: la construcción de derechos y obligaciones en la relación de los pueblos indígenas con las escuelas, ca. 1875-1940", Ariadna Acevedo describe las relaciones entre ciudadanos y Estado a partir de las expectativas, los derechos y las obligaciones que expresaban y practicaban los pobladores indígenas en la Sierra Norte de Puebla respecto de la escuela como institución del Estado, pensada para la educación de la población indígena. Acevedo realiza una breve revisión de conceptos de ciudadanía que revaloran lo particular y lo local, destacando que "lo local y lo nacional, más que oponerse y excluirse el uno al otro [...] mantienen una compleja relación y pueden complementarse el uno al otro" (p. 29). La escuela, diseñada desde el Estado como medio de homogeneización, pero utilizada por los ciudadanos para defender sus prácticas locales, es el espacio donde se articulan los distintos intereses de ambas partes.

Entre las prácticas de una "ciudadanía indígena", Ariadna Acevedo retoma "el sistema de cargos", las "peticiones" y "el pago de impuestos". En estas formas cotidianas de ejercer la ciudadanía se hallan elementos de educación de indígenas. El sistema de cargos como parte de esta educación cobró importancia cuando se trataba de realizar faenas o tequios en beneficio de las escuelas y para recaudar fondos. La "larga tradición de peticiones a autoridades superiores" (p. 34) fomentó el "uso de discursos de diversa proveniencia" (p. 35). El pago de impuestos para los servicios de la escuela anterior a la revolución creó conciencia sobre derechos y obligaciones. En este sentido, la experiencia de tener una escuela en la comunidad creó un "sentimiento de ciudadanía" (p. 26) y "formas cotidianas de ciudadanía que pueden ser muy distintas a los principios y prácticas de los gobiernos y el Estado sobre la ciudadanía y la población indígena" (p. 25). 
En "Ciudadanía y escuela en un pueblo mazahua del Estado de México, 1920-1943", Carlos Escalante explica los conceptos de ciudadano en las constituciones mexiquenses desde el siglo XIX hasta la promulgada en 1917, que incluyó por primera vez un artículo referente a la educación para indígenas en dicha entidad. En este contexto, el autor presenta "visiones sobre los indígenas" desde los estereotipos racistas de origen colonial hasta el término "inditos", usual en la época que investigó, como un sinónimo de atraso económico y cultural.

Escalante contrasta las políticas y prácticas educativas del Estado posrevolucionario, centradas en la enseñanza del español, con iniciativas de comuneros mazahuas que defendieron su derecho a la escuela ante el peligro de que se cerrara por falta de interés de los pobladores. Mediante faenas y recaudación de fondos económicos, demostraron su compromiso y obligaron al Estado a "que fuesen respetadas sus decisiones" (p. 68).

Por su parte, Alicia Civera, en "Honores y ultrajes a la bandera: la escuela entre la democracia y la intolerancia en el México de los años cuarenta", retoma la historia de determinados acontecimientos de la Escuela Regional Campesina de Ayotzinapa, hoy conocida como Normal de Ayotzinapa, cuyos estudiantes fueron agredidos, en meses recientes, por fuerzas armadas del Estado, es un ejemplo de la coexistencia y los enfrentamientos entre las fuerzas hegemónicas y las liberadoras, ambas presentes desde los inicios de la escuela como institución del Estado. Al respecto, teóricos como Freire y Giroux hablan de las fuerzas emancipatorias de la escuela frente a la reproducción de las relaciones asimétricas de poder entre el Estado y sus ciudadanos.

En similitud con Ariadna Acevedo, Alicia Civera entiende la ciudadanía a partir de "la forma en que los individuos construyen el Estado" (p. 71). En función de ello analizó las prácticas tanto de estudiantes, como de maestros y campesinos en cuanto a su organización, los derechos que ejercen y reclaman, al mismo tiempo que describe las contradicciones presentes en estos grupos en relación con el Estado. El corporativismo introducido por el Estado creó la organización de maestros y de estudiantes, hijos de campesinos, y probablemente en su mayoría eran indígenas, organización política que en determinadas ocasiones se utilizó también en contra de quienes la crearon. En este artículo se evidencian los logros de una formación ciudadana a partir de la escuela, cuando sus egresados transfieren este conocimiento al ámbito laboral en el campo y queda manifiesto cómo el Estado reprime estas prácticas ciudadanas cuando se cuestionan las suyas.

En contraste con los autores mencionados, quienes se basan sobre todo en la exploración de archivos e investigaciones precedentes, el artículo de Elsie Rockwell, "Cultura escrita, historias locales y otra lógica ciudadana: relatos de los vecinos mayores de Cuauhtenco, Tlaxcala", se basa en entrevistas a personas mayores que le cuentan sus experiencias con la escuela. Mientras "la alfabetización ha sido considerada condición ineludible de ejercer la ciudadanía" (p. 93), aquí se demuestra cómo los pobladores han practicado 
la ciudadanía sin saber escribir, y cómo la necesidad de defender y reclamar tierras los hizo aprender a leer y escribir, pero sin ayuda de la escuela.

En los relatos de ejercicio de la ciudadanía aparecen, por un lado, elementos de educación de los indígenas en cuanto a la organización y compromisos establecidos en asambleas, el nombramiento de comisiones de "manera rotativa e irrenunciable" (p. 114), la ocupación de cargos locales por parte de los líderes en gestiones comunitarias y la "necesidad de realizar actos de manera respetuosa y en público" (pp. 108-109).

Por otro lado, lo que resulta explícito entre los entrevistados son sus experiencias en las escuelas de educación para indígenas, en las que permanecieron por poco tiempo y en cuyas "aulas predominaba un español selectivo, ritualista y vinculado con la palabra escrita" (p. 99), mientras que la lengua náhuatl se excluía. Es así como las relaciones entre ciudadanos y Estado se gestaron a partir de las prácticas de los primeros y rebasaron lo que la escuela les pudo ofrecer.

En "Ciudadanos de la modernidad. El caso de los profesionistas de Zacán, Michoacán", Elizabeth M. Buenabad investigó un caso excepcional en cuanto a relaciones entre pobladores de una comunidad p'urhépecha y el Estado, donde el aprendizaje y ejercicio de ciudadanía no se generó tanto al margen o contra el Estado - como en los artículos anteriores-, sino en gran parte con el Estado. Por medio de muchísimas entrevistas a personas claves, Elizabeth Buenabad consigna las relaciones sociales con personas vinculadas con el Estado, quienes permitieron la profesionalización de una cantidad sobresaliente de los habitantes de Zacán, quienes se consideran a sí mismos como "ciudadanos exitosos". Los secretos de este éxito, entendido como ascenso social, fueron un dominio del español a partir de relaciones económicas y personales con hablantes de esta lengua, la oportunidad de una educación escolarizada fuera de su comunidad y no diseñada solamente para indígenas, facilitada por internados y becas, como parte de las políticas educativas de Lázaro Cárdenas, y en no pocos casos por su intervención personal.

El ser ciudadano está estrechamente vinculado con el ser profesionista y vivir en una ciudad, pero también con la gestión de "mejoras" a la comunidad de origen, gracias a las relaciones políticas y profesionales con personajes fundamentales del Estado y las asociaciones entre los profesionistas de Zacán (p. 131).

\section{Segunda sección}

El texto de Marco A. Calderón Mólgora, titulado "Educación indígena, experimentos sociales y ciudadanía: el caso de Actopan, Hidalgo, 1927-1931”, inicia con los orígenes de las prácticas indigenistas de un Estado con población altamente heterogénea (económica, 
política, social, cultural, lingüística y étnica), desde el proyecto Teotihuacán desarrollado por Manuel Gamio y las misiones culturales, para luego concretar este tipo de políticas en función de una homogeneización, no solamente cultural, como el caso de Actopan, que ilustra de diversas maneras quiénes fueron los actores, sus distintas formaciones, sus motivos y cómo interactuaban.

Lo que destaca del trabajo de Calderón Mólgora frente a otros escritos sobre esta misma temática es la exploración exhaustiva de archivos nacionales e internacionales, los cuales permitieron rastrear cómo la incorporación de científicos reconocidos de distintas disciplinas y el intercambio entre mexicanos y estadounidenses (estudiantes y profesionistas), acuñaron los proyectos educativos para los indígenas. Los intereses de aprender y trabajar en ambos países fueron compartidos por varios de esos estudiosos. Algunas de las metas expresadas por los actores de la misión indigenista fueron la formación de "mentes citadinas modernas" (p. 158) y la "rehabilitación económica y social de la población indígena" (p. 161). Este artículo enriquece la discusión sobre los inicios de la educación para indígenas, al ubicarla en un contexto internacional, en el que México fungió como ejemplo para Estados Unidos.

Retomando el interés de explorar las relaciones académicas e ideológicas que se dieron en esta época entre científicos mexicanos y estadounidenses, en "El pragmatismo indigenista de Moisés Sáenz o cómo encontrar ideas de John Dewey en Carapan. Bosquejo de una experiencia", Philippe Schaffhauser se propone buscar los vínculos entre el indigenismo mexicano y el pragmatismo estadounidense, un reto nada sencillo. Las personas del encuentro son John Dewey y Moisés Sáenz; el lugar, Carapan, comunidad p’urhépecha, donde Sáenz y su equipo llevaron a cabo un "experimento social" que suscitaría polémica, sobre todo a partir de las críticas que recibió por parte de sus pobladores. El autor busca en esta experiencia documentada por Sáenz los elementos del pragmatismo acuñado por Dewey, quien fuera maestro del primero en la Universidad de Columbia, en Nueva York.

En dicho artículo se describen los lineamientos pedagógicos del Proyecto Carapan, basados en el pragmatismo de Dewey, quien a su vez retomó a pensadores soviéticos como Vigotsky y Leontiev, como los motivos y las experiencias que llevaron a Sáenz a Carapan. Finalmente, se constata que "lejos de solucionar el problema educativo de la Cañada de los Once Pueblos, el proyecto de Carapan empezó a cambiar la condición social y educativa de los lugareños, volviéndolos un poco más mexicanos, es decir, mejores ciudadanos" (p. 201). En este caso, la calidad de la ciudadanía parece valorarse en términos de homogeneización de la población mexicana, una perspectiva también asumida por el Estado.

El artículo "Para que queden más firmes en la fe ¿o en la expresividad? Educación artística y teatro, bases para la formación de ciudadanos indígenas" de Elizabeth Araiza sirve como articulación de esta segunda sección con la primera, dando cuenta tanto de la perspectiva de los indígenas a través de entrevistas a mayores de edad que cuentan sus experiencias, así 
como de los intereses y apreciaciones de los representantes de la Secretaría de Educación Pública, a partir de una exploración extensa de archivos de esa institución, centrándose en la descripción de tres proyectos educativos apoyados en actividades artísticas en Teotihuacán, en Paracho y en la Casa del Estudiante Indígena de la ciudad de México.

Entre las diversas aportaciones de este texto, me permito resaltar una que, desde mi propia mirada, explica parte de las actividades escolares actuales y que, de cierta manera, tiene que ver con lo que un poeta alemán y teórico del teatro, Bertold Brecht, desarrolló con el objetivo de una educación ciudadana emancipatoria. Me refiero al efecto del distanciamiento, que se logra al presentar algo cotidiano y, por lo tanto, no fácilmente percibido y analizado, con elementos que lo vuelven extraño. Así, llama la atención, provoca reflexión y cuestiona lo dado. Algo parecido sucedió con el teatro etnográfico que pretendió que "el indio se haga inteligible a sí mismo" (p. 228), pero no incluyó, como la autora concluye, el "abordaje de los derechos ciudadanos" (p. 230). De estas prácticas de "distanciamiento" resultaron festivales folclóricos, presentando danzas de manera descontextualizada y, por lo tanto, sin tomar en cuenta los sentidos con los que se crearon. Cuando pretendieron que lo "mismo" se volviera "otro", para que el "mismo" fuera más consciente de sí mismo, el distanciamiento se volvió alienante en lugar de emancipar y la danza de los viejitos fue expropiada de sus sentidos para que los "Otros" le impusieran los suyos. 